\title{
Bridging the Gaps Between Patients and Primary Care in China: A Nationwide Representative Survey
}

\author{
William C. W. Wong, $M D^{1 *}$ \\ Sunfang Jiang, $M D^{2 *}$ \\ Jason J. Ong, $P b D^{3}$ \\ Mingbui Peng, $M D^{2}$ \\ Eric Wan, MSc ${ }^{1}$ \\ Shanzbu Zbu, $M D^{2}$ \\ Cindy L. K. Lam, $M D^{1}$ \\ Micbael R. Kidd, AM, MD $D^{4,5}$ \\ Martin Roland, $M D^{6}$ \\ *Equal contribution as co-first authors \\ 'Department of Family Medicine and \\ Primary Care, University of Hong Kong, \\ Hong Kong, China \\ ${ }^{2}$ General Practice Department, Fudan Uni- \\ versity, Shanghai, China
}

${ }^{3}$ Central Clinical School, Monash University, Melbourne, Australia

${ }^{4}$ Department of Family and Community Medicine, University of Toronto, Canada

${ }^{5}$ Faculty of Medicine, Nursing and Health Sciences, Flinders University, Australia

${ }^{6}$ Institute of Public Health, University of Cambridge School of Clinical Medicine, Cambridge, United Kingdom

Conflicts of interest: authors report none.

\section{CORRESPONDING AUTHOR}

William C. W. Wong, MD

Department of Family Medicine and Primary Care

The University of Hong Kong

3/F, 161 Main St

Ap Lei Chau Clinic

Ap Lei Chau, Hong Kong, China

wongwcw@hku.hk

\begin{abstract}
PURPOSE China introduced a national policy of developing primary care in 2009, establishing 8,669 community health centers (CHCs) by 2014 that employed more than 300,000 staff. These facilities have been underused, however, because of public mistrust of physicians and overreliance on specialist care.
\end{abstract}

METHODS We selected a stratified random sample of CHCs throughout China based on geographic distribution and urban-suburban ratios between September and December 2015. Two questionnaires, 1 for lead clinicians and 1 for primary care practitioners (PCPs), asked about the demographics of the clinic and its clinical and educational activities. Responses were obtained from 158 lead clinicians in CHCs and 3,580 PCPs (response rates of $84 \%$ and $86 \%$, respectively).

RESULTS CHCs employed a median of 8 physicians and 13 nurses, but only onehalf of physicians were registered as PCPs, and few nurses had training specifically for primary care. Although virtually all clinics were equipped with stethoscopes (98\%) and sphygmomanometers (97\%), only 43\% had ophthalmoscopes and 64\% had facilities for gynecologic examination. Clinical care was selectively skewed toward certain chronic diseases. Physicians saw a median of 12.5 patients per day. Multivariate analysis showed that more patients were seen daily by physicians in $\mathrm{CHCs}$ organized by private hospitals and those having pharmacists and nurses.

CONCLUSIONS Our survey confirms China's success in establishing a large, mostly young primary care workforce and providing ongoing professional training. Facilities are basic, however, with few clinics providing the comprehensive primary care required for a wide range of common physical and mental conditions. Use of $\mathrm{CHCs}$ by patients remains low.

Ann Fam Med 2017;15:237-245. https://doi.org/10.1370/afm.2034.

\section{INTRODUCTION}

$\mathrm{T}$ he importance of a strong primary care system providing first contact access, an emphasis on prevention, and person-focused comprehensive care with continuity and coordination is widely accepted. ${ }^{1-5}$ The World Health Report and World Health Organization (WHO) have highlighted additional key components underlying primary health care, including an emphasis on universal coverage, ${ }^{6,7}$ communityoriented perspectives, and governance supported by national health policies. Nonetheless, many countries have yet to develop effective and robust primary care since the Alma Ata Declaration in 1978 calling for increased national and international commitment to primary care. ${ }^{8}$ Primary care today is often still characterized by inadequately resourced facilities; lack of appropriate training ${ }_{i}$ inequalities in delivery of care, itself variable in quality; and fragmented care, which may be unsafe and often has little focus on prevention. ${ }^{6}$

In China, these problems have been compounded by a deterioration in physician-patient relationships resulting from economic and health systems reforms. ${ }^{9}$ Since the economic reforms in the late 1980 s involving fiscal decentralization, commercialization of medical services, and underfunding of the public health care sector, community health workers 
have turned to more profitable drugs and high-tech diagnostics. ${ }^{10,11}$ Tying physicians' compensation to their revenue-generating ability has led to overprescribing of highly priced and often unnecessary medical tests. ${ }^{12}$ In addition to ever-rising health care costs for patients, these factors have built unrealistic patient expectations focused on specialist diagnostic aids and procedures rather than cost-efficient primary care that would better suit the nation's health needs. ${ }^{13}$ Patients' perceptions of unfair treatment or financial exploitation have also led to reports of mistrust of and increasing violence toward health care professionals..$^{10,14}$

In 2009, the Chinese government recognized these fundamental problems and committed itself to reestablishing primary health care. ${ }^{15}$ By 2014, it had established 8,669 community health centers (CHCs) employing more than 300,000 health professionals $s_{i}$ however, the persistent negative image of "barefoot doctors" who had worked in rural regions since the 1950s, patients' criticism of the health care system, and unfavorable publicity by the media ${ }^{11}$ have led to a lack of trust even in the newly revamped primary care system. These problems seem particularly severe in cities, where patients have more choices and easier access to hospitals. The $\mathrm{CHCs}$ appear underused, primary care practitioners (PCPs) are sometimes poorly trained, and resources are unequally distributed even within primary care. This study aimed to evaluate the current quality of $\mathrm{CHCs}$ in China, including their organization and infrastructure, as well as their use by patients and training of their health care professionals in primary care.

\section{METHODS}

We conducted a nationwide representative survey using a stratified randomized sample among $\mathrm{CHC}$ medical professionals between September and December 2015. A local ethics board (HKU/HAW IRB: UW15-350) and the WHO Regional Office for the Western Pacific (2016.4.CHN.1.HSI) approved the study.

\section{CHC Sample}

We divided China into 3 administrative regions: central, eastern, and western. Two provinces were randomly selected from each region; within each region, we selected the capital city and randomly selected 2 district-level cities. In addition, 2 of the 4 municipalities (Beijing, Shanghai, Chongqing, and Tianjin) were also randomly selected and included in the sampling. In total, 20 cities were chosen from the province and municipalities combined, and from each city, $9 \mathrm{CHCs}$ were randomly selected (with an urban-to-suburban ratio of 2:1), giving a total of $180 \mathrm{CHCs}$. We invited the lead clinicians and all PCPs (including physicians and nurses) with direct patient contact from these selected CHCs to participate in our survey.

We contacted the local chairpersons of the General Practitioner Association of the 6 selected provinces and 2 selected municipalities, who in turn contacted the randomly selected CHCs. Training on how to distribute and complete the survey questionnaire was arranged for the coordinators of each province or municipality before the study to ensure survey quality. Designated individuals were responsible for sending out the questionnaires by mail and delivering them in person, and for collecting them at a later time. We contacted lead clinicians by telephone if no response was obtained within 2 weeks of questionnaire delivery. Collected data were entered and cleaned using EpiData 3.1 (EpiData Association). A data entry team was responsible for data input, and appointed personnel were responsible for auditing and quality control.

\section{Questionnaires}

Our survey used 2 questionnaires: 1 for only the lead clinician and 1 for all PCPs. The lead clinician questionnaire (Supplemental Appendix 1, available at http:// www.annfammed.org/content/15/3/237/suppl/DC1) covered the CHC's current clinical setup, range of services and manpower, community characteristics, and patient demographics, as well as its continuous professional development (CPD) and secondary care support. This questionnaire also asked the lead clinician to use his or her own records to estimate the median population size of the catchment area and the number of patient contacts in the past year.

The questionnaire for all PCPs asked about their working conditions, participation in CPD, and willingness to provide certain medical tests. Both nurses and physicians were surveyed because they are the core service clinicians at CHCs in China.

Both questionnaires were pilot-tested twice at 3 CHCs and among 25 PCPs, and modified accordingly.

\section{Analyses}

We performed descriptive analyses, calculating percentages and frequencies of key parameters. Confidence intervals for the sample proportions were calculated using the adjusted Wald method. Statistical modeling focused on (1) daily number of patients seen by each physician, (2) number of physicians, and (3) number of patients as a proxy measure of the match between human resources (ie, number of physicians working per day) and $\mathrm{CHC}$ use (ie, number of patients visiting the center per day). These values were also adjusted for region and population catchment area.

We used multivariate linear regression analysis to identify factors-among various measures of $\mathrm{CHC}$ 
structure, staff composition, number of services, and on-site testing — independently associated with the number of patients seen daily by each physician. The assumptions of the regression model_-normality of residuals, homoscedasticity, and multicollinearitywere checked by scatterplot of residuals vs predicted (fitted) values (quantile-quantile plots), Breusch-Pagan/ Cook-Weisberg tests, and a variance inflation factor, respectively. We used the $R^{2}$ value to assess the model's goodness of fit. All significance tests were 2-tailed, and those with a $P$ value $<.05$ were considered statistically significant.

Finally, multivariate logistic regression analysis was conducted to examine factors associated with the characteristics of $\mathrm{CHC}$ having above-median employment of physicians. We analyzed data with Stata software, release 13 (StataCorp LP).

\section{RESULTS}

Of the $189 \mathrm{CHC}$ s contacted, 158 provided data on their facility ( $84 \%$ response rate). Figure 1 shows the distribu- tion of CHCs surveyed. Of the 4,146 PCPs invited to participate, 1,734 physicians and 1,846 nurses completed questionnaires, giving a response rate of $86 \%$.

Table 1 shows the general characteristics of the CHCs. The median population size of the catchment area of each $\mathrm{CHC}$ was 50,000 people (interquartile range $[\mathrm{IQR}], 30,000-96,000)$ with a migrant population of 11,100 (IQR, 5,000-30,000). The median number of patient contacts per year was 41,100 (IQR, $12,000-163,600)$. The majority of CHCs had been converted from a Class B hospital (58\%) or Class C hospital (13\%). Three-quarters of them $(77 \%$; $95 \% \mathrm{CI}$, $70 \%-83 \%)$ were open 7 days a week. Slightly less than two-thirds $(62 \% ; 95 \% \mathrm{CI}, 54 \%-70 \%)$ operated through an appointment system. Physicians saw a median of 12.5 patients a day (IQR, 5.0-25.8).

Table 2 shows human and material resources of the CHCs. They had a fairly high ratio of nurses to physicians, at 1.7 (IQR, 1.0-2.8), but less commonly employed administrative and allied health staff. Basic primary care equipment, including stethoscopes, sphygmomanometers, and thermometers, were

\section{Figure 1. Distribution of community health centers surveyed across China.}

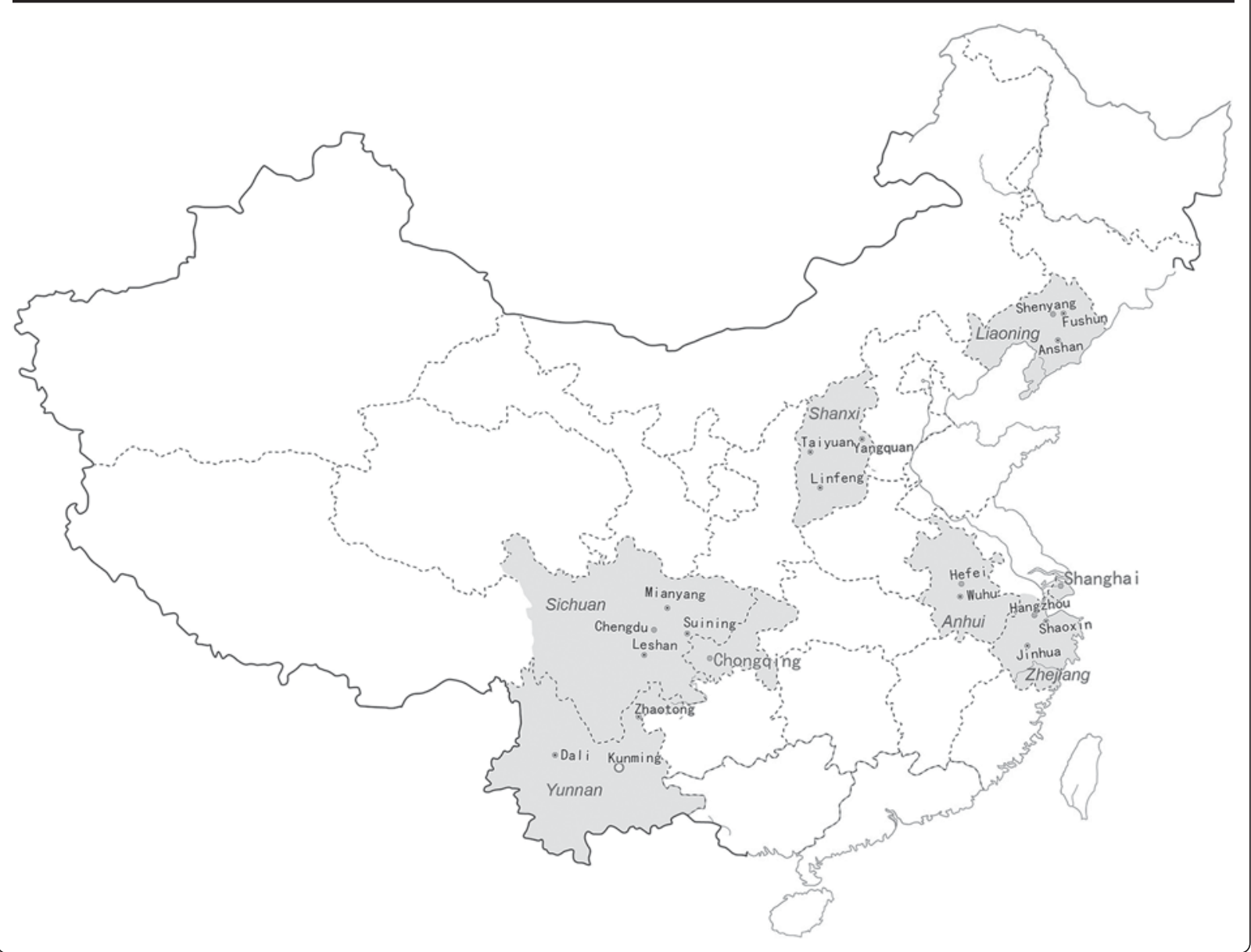


Table 1. General Characteristics of the CHCs $(\mathrm{N}=149)$

\begin{tabular}{lc}
\hline Characteristic & Value \\
\hline Population size, median (IQR) & \\
$\quad$ Catchment area & $50,000(30,000-96,000)$ \\
$\quad$ Migrant population & $11,100(5,000-30,000)$ \\
Days open per week, median (IQR) & $7(7-7)$ \\
Patient visits in 2014, median No. (IQR) & $41,100(12,000-16,360)$ \\
Age of patients, mean (SD), y & $49.9(11.1)$ \\
Male-female ratio of patients, median (IQR) & $1(0.7-1.3)$ \\
Patients seen each day, median No. (IQR) & $70(28-200)$ \\
Patients seen each day by physicians, mean No. (\%) & \\
$<10$ & $61(44.5)$ \\
10-19.9 & $27(19.7)$ \\
$20-39.9$ & $30(21.9)$ \\
$\geq 40$ & $19(13.9)$ \\
Physicians available each day, median No. (IQR) & \\
All physicians & $7(4-12)$ \\
Trained in western medicine & $5(2-10)$ \\
Trained in traditional Chinese medicine & $2(1-4)$ \\
Specialists & $2(1-4)$ \\
Appointments can be made in advance, \% (95\% CI) & $62(54-70)$ \\
Origin of CHC, \% (95\% CI) & \\
Converted from Class B or C hospital & $58(50-65)$ \\
Organized under Class B or C hospital & $13(8-18)$ \\
Organized under company, social group, or indi- & $31(23-38)$ \\
$\quad$ viduals (private enterprise) & \\
\hline CHC community health center; IQR = interquartile range. & \\
\hline & \\
\hline
\end{tabular}

a monthly or more frequent basis. Virtually all these meetings involved physicians, nurses, and mangers, but few involved other health care staff or receptionists. These meetings covered organization and service management $(97 \%)$, policy implementation $(100 \%)$, team performance $(95 \%)$, organization of work processes and services $(96 \%)$, disease updates $(84 \%)$, case discussions $(83 \%)$, and further medical education courses $(96 \%)$.

Table 4 details differences in $\mathrm{CHC}$ characteristics according the 3 regions. $\mathrm{CHCs}$ in the eastern region appeared to be better developed and used than those in the western and central regions in that they had significantly higher population catchment area $(P=.03)$, and person-time visits $(P<.01)$. The mean age of $\mathrm{CHC}$ staff in the eastern region was older $(P=.02)$ and there were more physicians registered as general practitioners $(P<.01)$, and more managers/administrators $(P=.01)$, pharmacists $(P<.01)$, and laboratory technicians $(P<.01)$. There were no statistical differences among the 3 regions with respect to the number of receptionists $(P=.70)$, computers for keeping medical records available, but sizable shares of CHCs did not have spotlights for gynecologic examination (36\%), ophthalmoscopes $(57 \%)$, or otoscopes (17\%). The great majority of consultation rooms had access to computerized medical records (88\%) including Internet access $(81 \%)$. Nearly all CHCs had on-site capacity for further tests (biochemistry/hematology) (95\%) and ultrasound (91\%). Most had inpatient beds for their patients $(87 \%)_{i}$ however, only $38 \%$ had microbiology support and only 53\% offered Papanicolaou (Pap) screening. Although virtually all $\mathrm{CHCs}$ provided management of common ailments, chronic diseases, hypertension, and diabetes, as well as traditional Chinese medicine, maternal and infant health care, and vaccinations, large proportions did not provide management for other common conditions such as dyslipidemia (38\%), mental illness (66\%), sexually transmitted infections (66\%), and chronic obstructive pulmonary disease (70\%).

Table 3 provides an overview of the responses from PCPs. On average, the physicians and nurses surveyed were 39.7 and 33.1 years old, respectively. About one-half (54\%) of the physicians had a graduate degree or more education, but only $46 \%$ reported that general practice was their primary registration. In terms of ongoing professional development, two-thirds of $\mathrm{CHCs}$ provided $\mathrm{CPD}$ to improve patient care on
$(P=.47)$, appointment systems $(P=.99)$, or being open 7 days a week $(P=.07)$. They also did not differ in terms of certain staff, such as number of receptionists $(P=.70)_{i}$ facilities, such as drug-dispensing facilities $(P=.59)$, treatment rooms $(P=.76)$, access to inpatient beds $(P=.12)$, designated parking facilities $(P=.55)$; or Internet access for staff $(P=.38)$. Across regions, $\mathrm{CHCs}$ were also statistically indistinguishable with respect to their range of services, for example, offering chronic disease management $(P=.26)$, family planning and reproductive health $(P=.91)$, maternity and infant health $(P=.90)$, vaccinations $(P=.16)$, mental health care $(P=.36)$, on-site blood testing $(P=.49)$, and on-site radiography $(P=.59)$.

Table 5 summarizes the multivariate analysis of $\mathrm{CHC}$ characteristics associated with a higher mean number of patients seen daily by each physician. Physicians saw more patients daily in CHCs that had been converted from private hospitals and those having more pharmacists and nurses ${ }_{i}$ in contrast, physicians saw fewer patients daily in CHCs that offered more services or were open more days per week. Table 6 shows the analysis of factors associated with $\mathrm{CHC}$ employment of more than the median number of 7 physicians per day. $\mathrm{CHCs}$ were less likely to have above-median physician employment if they originated 
from a private enterprise, and more likely to do so if they employed more specialists and nurses, and if they offered more services.

\section{DISCUSSION}

This is the first nationally representative survey of the structure and organization of the Chinese primary health care system, involving $158 \mathrm{CHCs}$ and more than 3,500 PCPs. We found the surveyed CHCs to be generally well equipped, but some physicians were neither trained to use nor used otoscopes or ophthalmoscopes in their clinical examination. The lack of some simple equipment may reflect the selected service provided in primary care, for example, the relative lack of spotlights for gynecologic examination likely reflects the lack of availability of Pap testing in this setting. Other countries have also noted lack of basic services in their primary health care, such as a shortfall of mental health screening in Canada and Australia. ${ }^{16,17}$ On one hand, these young PCPs were actively engaged in professional development and quality improvement of their clinics. On the other hand, use of services by patients remained poor at each $\mathrm{CHC}$ : despite serving 50,000 people, the centers had an average of only 41,000 patient contacts a year, and each physician saw a median of just 12.5 patients per day. Staffing varied considerably across regions, with the eastern $\mathrm{CHCs}$ employing more staff and types of staff, but equipment, facilities, and services offered varied little.

China has recently been implementing strategies to strengthen its primary health care system to prepare for and improve universal coverage. According to the Health \& Family Planning Commission, expenditure on primary care reached $¥ 110$ billion $(1 \mathrm{USD}=¥ 6.20)$ in $2014 .{ }^{18}$ In fewer than 10 years, the Chinese government has succeeded in establishing a primary medical care service infrastructure composed mainly of rural township centers, village clinics, and CHCs in cities. In 2011, social insurance was passed to provide for equal access to basic public health services for both urban and rural residents. ${ }^{19}$ Historically, a variety of colleges, vocational training schools, and universities have offered medical courses ranging from 2 to 8 years of training. Graduates of these courses would have to pass board examinations to be registered for their chosen specialties. The young discipline of general practice in China was reflected by the relatively young age and junior titles reported by our survey respondents, clinicians

Table 2. CHC Staff, Equipment, Facilities, Services, and Testing

\begin{tabular}{|c|c|}
\hline Characteristic & Value \\
\hline \multicolumn{2}{|l|}{ Staff, median No. (IQR) } \\
\hline Full-time general practitioners & $8(4-14)$ \\
\hline Part-time general practitioners & $0(0-2)$ \\
\hline Dentists & $1(0-2)$ \\
\hline Nurses & $13(8-21)$ \\
\hline Managers/administrators & $2(1-3)$ \\
\hline Front desk administrators/receptionists & $1(0-1)$ \\
\hline Pharmacists & $2(1-5)$ \\
\hline Physiotherapists & $1(0-2)$ \\
\hline Psychologists & $0(0-0)$ \\
\hline Social workers & $0(0-1)$ \\
\hline Laboratory technicians & $2(1-3)$ \\
\hline Radiographers & $1(1-2)$ \\
\hline \multicolumn{2}{|l|}{ Equipment in consultation rooms, $\%(95 \% \mathrm{Cl})$} \\
\hline Stethoscope & $98(96-100)$ \\
\hline Sphygmomanometer & $97(95-100)$ \\
\hline Thermometer & $96(93-99)$ \\
\hline Computer for keeping medical records & $88(83-93)$ \\
\hline Otoscope & $83(73-93)$ \\
\hline Spotlight for gynecologic examination & $64(56-71)$ \\
\hline Ophthalmoscope & $43(35-52)$ \\
\hline \multicolumn{2}{|l|}{ Facilities available, \% (95\% Cl) } \\
\hline Observation/intravenous drug room & $100(97-100)$ \\
\hline Treatment/wound dressing room & $93(89-97)$ \\
\hline Inpatient beds & $87(81-92)$ \\
\hline Drug dispensing & $84(78-90)$ \\
\hline Internet access for staff & $81(75-88)$ \\
\hline Designated parking facilities & $78(72-85)$ \\
\hline Wheelchair access & $77(70-84)$ \\
\hline \multicolumn{2}{|l|}{ Clinical services for various conditions, \% (95\% Cl) } \\
\hline Common ailments (cold, diarrhea) & $100(97-100)$ \\
\hline Chronic disease management (hypertension, diabetes) & $99(96-100)$ \\
\hline Traditional Chinese medicine & $96(93-99)$ \\
\hline Maternity and infant health care & $93(89-97)$ \\
\hline Vaccinations & $93(89-97)$ \\
\hline Family planning/reproductive health & $79(72-86)$ \\
\hline Dyslipidemia management & $62(55-70)$ \\
\hline Sexually transmitted infection diagnosis and management & $34(26-42)$ \\
\hline Mental health care & $34(26-41)$ \\
\hline Chronic obstructive pulmonary disease management & $30(23-38)$ \\
\hline \multicolumn{2}{|l|}{ Testing available, \% (95\% Cl) } \\
\hline Blood tests (biochemistry, hematology) & $95(91-98)$ \\
\hline Doppler/ultrasound & $91(86-95)$ \\
\hline Rapid pregnancy test & $87(81-92)$ \\
\hline Radiographs & $75(68-82)$ \\
\hline Papanicolaou test & $53(45-61)$ \\
\hline Microbiology & $38(30-46)$ \\
\hline
\end{tabular}


who were often originally trained as specialists but were tasked with setting up these CHCs. Indeed, onehalf of the physicians in our study kept their previous specialist registration despite the fact that all were now working in primary care. In light of this situation, there is concern that these professionals may not feel allegiance to their new roles and identities in an interprofessional rivalry, resulting in lack of alignment with the community's needs or health system functioning. One example is that the services seen were skewed on management of certain chronic diseases, and on performance of some unappealing public health tasks, such as setting up detailed chronic disease computer records, which is paid for by the government.

Basic primary care teams in China are made up of physicians, including traditional Chinese medicine practitioners, as well as nurses, with very few physiotherapists, clinical psychologists, or social workers. The CHC workforce is determined to some degree by a combination of the local health bureau requirements to fulfill basic manpower needs, but largely by the hospital with which the center is affiliated. These $\mathrm{CHCs}$ provide selected primary care services for common ailments, chronic diseases, and preventive care, such as vaccinations. The lack of a diverse multidisciplinary primary care team that allows roles to be defined in a functional response to the needs of the community is evident in this study. As many CHCs had been converted from smaller township (Class B and C) hospitals, a broader range of facilities (including inpatient beds or radiograph/ultrasound capability) were offered. Our findings contrast with the general public's perception of CHCs as "poorly equipped and of low quality." ${ }^{120}$ We found underuse of $\mathrm{CHCs}_{\text {; }}$ in fact, those offering more services and open longer hours were not more acceptable and used to greater extent by patients in our study. These findings suggest that patients are not supportive of community health work-
Table 3. Characteristics of the CHCs' Primary Care Practitioners and Continuing Education

\begin{tabular}{|c|c|c|c|}
\hline Characteristic & Lead Clinicians & Physicians & Nurses \\
\hline \multicolumn{4}{|l|}{ Sociodemographics } \\
\hline Age, mean (SD), y & - & $39.7(10.6)$ & $33.1(8.9)$ \\
\hline Male, \% (95\% Cl) & - & $39(37-41)$ & $1(0-2)$ \\
\hline Han Chinese, \% $(95 \% \mathrm{Cl})$ & - & $95(94-96)$ & $95(94-96)$ \\
\hline \multicolumn{4}{|l|}{ Highest qualification, \% (95\% Cl) } \\
\hline Less than associate degree & - & $12(10-13)$ & $21(19-23)$ \\
\hline Associate degree & - & $34(31-36)$ & $50(48-52)$ \\
\hline Graduate degree & - & $49(47-52)$ & $26(24-28)$ \\
\hline $\begin{array}{l}\text { Graduate degree with postgraduate } \\
\text { qualifications }\end{array}$ & - & $6(5-7)$ & $3(2-4)$ \\
\hline \multicolumn{4}{|l|}{ Primary specialty registration, \% (95\% Cl) } \\
\hline General practice & - & $46(44-48)$ & $5(4-6)$ \\
\hline Integrative medicine & - & $8(7-10)$ & 0 \\
\hline Other specialty & - & $26(24-28)$ & $1(1-2)$ \\
\hline Years working, median (IQR) & - & $14(7-23)$ & $9(4-18)$ \\
\hline \multicolumn{4}{|l|}{ Title, \% (95\% Cl) } \\
\hline Senior & - & $10(9-12)$ & $2(2-3)$ \\
\hline Intermediate & - & $41(39-43)$ & $26(24-28)$ \\
\hline Junior & - & $40(38-43)$ & $64(61-66)$ \\
\hline None & - & $9(7-10)$ & $8(7-9)$ \\
\hline $\begin{array}{l}\text { Participation in continuing education, } \\
\%(95 \% \mathrm{Cl})\end{array}$ & - & $92(91-93)$ & $89(88-91)$ \\
\hline \multicolumn{4}{|l|}{ Frequency of CPD, \% (95\% Cl) } \\
\hline Yearly & $12(7-17)$ & - & - \\
\hline Quarterly & $18(12-24)$ & - & - \\
\hline Bimonthly & $10(5-15)$ & - & - \\
\hline Monthly & $52(44-60)$ & - & - \\
\hline Biweekly & $11(6-16)$ & - & - \\
\hline Weekly & $3(0-5)$ & - & - \\
\hline \multicolumn{4}{|l|}{ Professionals partaking in CPD, \% $(95 \% \mathrm{Cl})$} \\
\hline Managers & $95(92-99)$ & - & - \\
\hline Physicians & $100(97-100)$ & - & - \\
\hline Nurses & $100(97-100)$ & - & - \\
\hline Other health care staff & $88(82-93)$ & - & - \\
\hline Receptionists & $61(52-69)$ & - & - \\
\hline \multicolumn{4}{|l|}{ Content of CPD, \% (95\% Cl) } \\
\hline Studies/discussion on diagnostic standards & $96(93-99)$ & $86(85-88)$ & $64(62-67)$ \\
\hline Disease updates & $84(78-90)$ & $80(78-82)$ & $63(60-65)$ \\
\hline Case discussions & $83(77-89)$ & $78(76-80)$ & $57(55-60)$ \\
\hline Further medical education courses & $96(93-99)$ & $92(91-93)$ & $88(86-89)$ \\
\hline \multicolumn{4}{|l|}{$\begin{array}{l}\text { Content of management meetings, } \\
\%(95 \% \mathrm{Cl})\end{array}$} \\
\hline Organizing and managing services & 97 (94-100) & - & - \\
\hline $\begin{array}{l}\text { Conveying and implementing policies } \\
\text { and documents }\end{array}$ & $100(97-100)$ & - & - \\
\hline $\begin{array}{l}\text { Appraising department and team } \\
\text { performance }\end{array}$ & $95(91-98)$ & - & - \\
\hline
\end{tabular}


Table 4. Differences in CHC Characteristics According to Region

\begin{tabular}{|c|c|c|c|c|}
\hline Characteristic & East $(n=56)$ & West $(n=47)$ & Central $(n=46)$ & $\begin{array}{c}P \\
\text { Value }\end{array}$ \\
\hline \multicolumn{5}{|l|}{ Provision of care } \\
\hline Population of catchment area, median (IQR) & $60,000(37,000-100,000)$ & $60,500(31,500-100,000)$ & $30,000(21,000-72,000)$ & .03 \\
\hline Annual person-time visits, median No. (IQR) & $125,000(28,150-275,500)$ & $44,500(17,300-111,000)$ & $11,250(4,750-42,500)$ & $<.01$ \\
\hline \multicolumn{5}{|l|}{ Facilities, $\%(95 \% \mathrm{Cl})$} \\
\hline Computers for keeping medical records & $81(71-91)$ & $90(82-98)$ & $86(77-96)$ & .47 \\
\hline Appointments can be made in advance & $61(48-74)$ & $62(49-76)$ & $61(48-75)$ & .99 \\
\hline Open 7 days a week & $77(66-87)$ & $82(72-93)$ & $64(51-77)$ & .07 \\
\hline Drug-dispensing facilities & $80(69-90)$ & $82(71-93)$ & $86(77-96)$ & .59 \\
\hline Treatment rooms & $90(82-98)$ & $92(85-100)$ & $92(84-100)$ & .76 \\
\hline Inpatient beds & $81(71-91)$ & $92(85-100)$ & $81(70-92)$ & .12 \\
\hline Designated parking & $81(72-91)$ & $75(63-87)$ & $74(61-86)$ & .55 \\
\hline Internet access for staff & $84(75-94)$ & $80(70-91)$ & $74(62-86)$ & .38 \\
\hline \multicolumn{5}{|l|}{ Staff composition, median (IQR) } \\
\hline Age of staff, y & $55(47-60)$ & $50(42-54)$ & $49(41-55)$ & .02 \\
\hline $\begin{array}{l}\text { Physicians registered as general practitio- } \\
\text { ners, No. }\end{array}$ & $5(2-12)$ & $2(1-7)$ & $2(1-3)$ & $<.01$ \\
\hline Administrators/managers, No. & $3(1-5)$ & $2(1-3)$ & $1(1-2)$ & .01 \\
\hline Receptionists, No. & $1(0-1)$ & $1(0-2)$ & $1(0-1)$ & .70 \\
\hline Pharmacists, No. & $5(2-8)$ & $2(1-4)$ & $2(1-3)$ & $<.01$ \\
\hline Laboratory technicians, No. & $3(2-4)$ & $2(1-2)$ & $2(1-2)$ & $<.01$ \\
\hline \multicolumn{5}{|l|}{ Services available, $\%(95 \% \mathrm{Cl})$} \\
\hline Chronic disease management & $100(93-100)$ & $100(92-100)$ & $97(87-100)$ & .26 \\
\hline Family planning and reproductive services & $79(68-90)$ & $76(64-88)$ & $78(66-89)$ & .92 \\
\hline Maternity and infant health & $92(85-99)$ & $92(85-100)$ & $90(82-98)$ & .90 \\
\hline Vaccinations & $98(90-100)$ & $90(82-98)$ & $86(76-96)$ & .16 \\
\hline Mental health care & $39(26-51)$ & $37(23-50)$ & $27(14-40)$ & .36 \\
\hline On-site blood tests & $98(90-100)$ & $92(85-100)$ & $90(82-98)$ & .49 \\
\hline On-site radiographs & $72(60-84)$ & $78(67-90)$ & $70(57-83)$ & .59 \\
\hline
\end{tabular}

ers even though these clinicians make services available in a primary care setting. Although $\mathrm{CHC}$ s converted from private hospitals saw more patients, their overall clinical expertise was poor compared with that of government-run or hospital-managed CHCs. ${ }^{21} \mathrm{Argu}-$ ably, setting up primary care services in big hospitals with the support of tests and procedures, and specialists could be an additional transition measure to introduce general practice and help patients gain trust in this "new" discipline. ${ }^{22}$

As primary care is a relatively new discipline to medical schools in China, very few of them have general practice departments; additionally, exposure to primary care at the undergraduate level is minimal, a situation further compounded by the low status of the discipline. Currently, full-time general practice vocational training requires 3 years, often with 2.5 years in hospital rotations and only 6 months working in the community. Despite these inherent disadvantages, the training programs suggested by the list of CPD activities we found in our sample appear to facilitate com- petencies required to address the local community's health needs and priorities, rather than replicating ideas and curriculum from resource-rich contexts. ${ }^{23}$

The main limitation of our study is that we collected only self-reported information on structure and use of care, and the survey did not include questions on primary care and health system reform from the perspective of China's leaders or patients. Nonetheless, this study is the first step in understanding the organization and delivery of primary care in China. The strengths are that the data were collected from a large sample of both physicians and nurses in CHCs throughout China, with good response rates at clinic and individual levels, and hence should be generalizable.

In China, as elsewhere, policy and training are the keys to high-quality primary health care; however, because of historic and recent mishaps in the Chinese health care system, policymakers will have to reconceptualize and change the system in these 2 areas, and also convey clearly the process and outcomes of 
Table 5. CHC Characteristics Associated With Number of Patients Each Physician Saw Per Day

\begin{tabular}{|c|c|c|}
\hline Characteristic & Coefficient $(95 \% \mathrm{Cl})$ & $\begin{array}{c}P \\
\text { Value }\end{array}$ \\
\hline \multicolumn{3}{|l|}{ Structure of $\mathrm{CHC}$} \\
\hline $\begin{array}{l}\text { Size of catchment area } \\
\text { (per 10,000-person } \\
\text { increment) }\end{array}$ & $-0.01(-0.03$ to 0.01$)$ & .46 \\
\hline \multicolumn{3}{|l|}{ Origin of $\mathrm{CHC}$} \\
\hline $\begin{array}{l}\text { Converted from Class } \\
\text { B/C hospital }\end{array}$ & $5.20(-3.58$ to 13.99$)$ & .24 \\
\hline Private enterprise & 11.05 (1.28 to 20.82 ) & $.03^{\mathrm{a}}$ \\
\hline $\begin{array}{l}\text { Number of days open } \\
\text { per week }\end{array}$ & $-3.76(-7.24$ to -0.28$)$ & $.04^{\mathrm{a}}$ \\
\hline \multicolumn{3}{|l|}{$\begin{array}{l}\text { Daily staff composition } \\
\text { (per 1-staff member } \\
\text { increment) }\end{array}$} \\
\hline Pharmacists & 1.89 (0.72 to 3.06$)$ & $.002^{\mathrm{a}}$ \\
\hline Specialists & $-0.08(-0.86$ to 0.71$)$ & .85 \\
\hline Dentists & $0.52(-2.23$ to 3.26$)$ & .70 \\
\hline Nurses & 0.32 (0.12 to 0.52$)$ & $.002^{\mathrm{a}}$ \\
\hline Managers & $0.10(-0.70$ to 0.89$)$ & .81 \\
\hline \multicolumn{3}{|l|}{ Services available } \\
\hline Number of services ${ }^{b}$ & $-3.28(-5.81$ to -0.76$)$ & $.01^{\mathrm{a}}$ \\
\hline \multicolumn{3}{|l|}{ On-site testing available } \\
\hline Radiography & $-1.03(-8.22$ to 6.16$)$ & .78 \\
\hline Blood testing & $4.18(-13.57$ to 21.92$)$ & .64 \\
\hline Ultrasound & $2.00(-11.72$ to 15.72$)$ & .77 \\
\hline Hepatitis B serology & $-5.16(-14.36$ to 4.04$)$ & .27 \\
\hline Rapid HIV test & $-5.21(-11.84$ to 1.42$)$ & .12 \\
\hline Rapid pregnancy test & $-2.30(-12.22$ to 7.63$)$ & .65 \\
\hline Rapid syphilis test & $4.42(-1.64$ to 10.48$)$ & .15 \\
\hline
\end{tabular}

$\mathrm{CHC}=$ community health center.

a $P<.05$ by multivariate linear regression analysis.

${ }^{b}$ Out of 7 possible services: traditional Chinese medicine, sexually transmitted infections diagnosis and management, drug dispensing, family planning/ reproductive health, maternal and infant care services, vaccination services, and mental health care.

these changes to the public to alter their perception of primary care. There is a need to develop tools to evaluate primary care activities more clearly, integrate community-orientated thinking into primary care, and teach an integrated comprehensive approach (eg, formation of multidisciplinary teams), rather than selected care and a purely biomedical approach. Interprofessional education should engage the key primary care clinicians early on in a collaborative, complex, adaptive approach to forming functional teams that meet the community's needs. ${ }^{24}$

To read or post commentaries in response to this article, see it online at http://www.AnnFamMed.org/content/15/3/237.

Key words: structure of care; delivery of care; quality of care; primary care; health personnel; patient acceptance of health care; China

Submitted May 25, 2016; submitted, revised, September 29, 2016; accepted October 19, 2016
Table 6. CHC Characteristics Associated With Above-Median Employment of Physicians

\begin{tabular}{|c|c|c|}
\hline Characteristic & Coefficient $(95 \% \mathrm{Cl})$ & $\begin{array}{c}P \\
\text { Value }\end{array}$ \\
\hline \multicolumn{3}{|l|}{ Structure of $\mathrm{CHC}$} \\
\hline $\begin{array}{l}\text { Size of catchment area } \\
\text { (per 10,000-person } \\
\text { increment) }\end{array}$ & $0.00(0.00$ to 0.01$)$ & .19 \\
\hline \multicolumn{3}{|l|}{ Origin of $\mathrm{CHC}$} \\
\hline Private enterprise & $-1.84(-3.60$ to -0.08$)$ & $.04^{a}$ \\
\hline \multicolumn{3}{|l|}{$\begin{array}{l}\text { Daily staff composition } \\
\text { (per 1-staff member } \\
\text { increment) }\end{array}$} \\
\hline Specialists & $0.51(0.18$ to 0.83$)$ & $.002^{\mathrm{a}}$ \\
\hline Nurses & $0.24(0.11$ to 0.37$)$ & $<.001^{\mathrm{a}}$ \\
\hline \multicolumn{3}{|l|}{ Services available } \\
\hline Number of services ${ }^{b}$ & $1.04(0.25$ to 1.83$)$ & $.01^{a}$ \\
\hline \multicolumn{3}{|l|}{$\mathrm{CHC}=$ community health center. } \\
\hline \multicolumn{3}{|c|}{$\begin{array}{l}\text { Note: The median number of physicians the CHCs employed was } 7 . \\
\text { a } P<.05 \text { by multivariate logistic regression analysis. } \\
\text { b Out of } 7 \text { possible services: traditional Chinese medicine, sexually transmit- } \\
\text { ted infection diagnosis and management, drug dispensing, family planning/ } \\
\text { reproductive health, maternal and infant care services, vaccination services, } \\
\text { and mental health care. }\end{array}$} \\
\hline
\end{tabular}

Funding support: This project is supported by 3 funding sources: (1) RGC Seed fund for basic research, University Grant Council, HK SAR Government, entitled "Survey of the attitudes and needs of integrated HIV and STI services in community health centres in China (2015-16)" (project no. 201411159004); (2) the Shanghai Key Discipline Construction Program in Public Health (Shanghai Municipal Commission of Health and Family Planning, project no. 12GWZX1001); and (3) the Shanghai Excellent Academic Leaders Training Program in Public Health (Shanghai Municipal Commission of Health and Family Planning, project no. GWDTR201210).

Acknowledgments: We thank the General Practice Society of Chinese Medical Association for offering assistance to organize this study. The biggest thanks is given to the experts of General Practice Society of the provinces and municipalities, including Prof. Dongdong Chen (Shanghai), Prof. Bo Xie (Chongqing), Prof. Xiaosong Yu \& Prof. Shuang Wang (Liaoning), Prof. Lizheng Fang (Zhejiang), Prof. Mei Feng (Shanxi), Prof. Guangbin Zhao (Sichuan), Prof. Haiqin Tang \& Prof. Jing Rui (Anhui), and Prof. Li He (Yunnan), who provided the communication with the $\mathrm{CHCS}$ and the investigation implementation. We also thank all the CHCs and physicians and nurses who participated in the survey.

Supplementary materials: Available at http://www.AnnFamMed. org/content/15/3/237/suppl/DC1/.

\section{References}

1. Fendall NR. Declaration of Alma-Ata. Lancet. 1978;2(8103):1308.

2. Starfield B, Shi L, Macinko J. Contribution of primary care to health systems and health. Milbank Q. 2005;83(3):457-502.

3. Kringos $D$, Boerma W, Bourgueil $Y$, et al. The strength of primary care in Europe: an international comparative study. Br J Gen Pract. 2013;63(616):e742-e750.

4. Pelone F, Kringos DS, Spreeuwenberg P, De Belvis AG, Groenewegen PP. How to achieve optimal organization of primary care service delivery at system level: lessons from Europe. Int J Qual Health Care. 2013;25(4):381-393 
5. Doubova SV, Guanais FC, Pérez-Cuevas R, Canning D, Macinko J, Reich MR. Attributes of patient-centered primary care associated with the public perception of good healthcare quality in Brazil, Colombia, Mexico and El Salvador. Health Policy Plan. 2016;31(7):834-843.

6. World Health Organization (WHO). The World Health Report 2008-Primary Health Care (Now More Than Ever). Geneva, Switzerland: WHO; 2008. http://www.who.int/whr/2008/en/. Accessed Apr 26, 2017.

7. World Health Organization (WHO). The World Health Report 2013. Research for Universal Health Coverage. Geneva, Switzerland: WHO; 2014. http://www.who.int/whr/2013/report/en/. Accessed Apr 26, 2017.

8. Hall JJ, Taylor R. Health for all beyond 2000: the demise of the Alma-Ata Declaration and primary health care in developing countries. Med J Aust. 2003;178(1):17-20.

9. World Health Organization (WHO). Western Pacific Region. Health Service Delivery Profiles: China. Manila, Philippines. 2012. http://www.wpro.who.int/health_services/health_service_delivery_ profiles/en/. Accessed Apr 26, 2017.

10. Yao S, Zeng Q, Peng M, Ren S, Chen G, Wang J. Stop violence against medical workers in China. J Thorac Dis. 2014;6(6):E141-E145.

11. Wagstaff A, Lindelow M, Wang S, Zhang S. Reforming China's Rural Health System. Washington, DC: The World Bank; 2009.

12. Ramesh $M, W u X$, He AJ. Health governance and healthcare reforms in China. Health Policy Plan. 2014;29(6):663-672.

13. Tucker JD, Cheng Y, Wong B, et al; Patient-Physician Trust Project Team. Patient-physician mistrust and violence against physicians in Guangdong Province, China: a qualitative study. BMJ Open. 2015; 5(10):e008221.

14. Zhu L, Xu C. Practice on strengthening hospital connotation construction and reducing medical disputes. Chinese Hospitals 2013;2(30).
15. Chen Z. Launch of the health-care reform plan in China. Lancet. 2009;373(9672):1322-1324.

16. Craven MA, Bland R. Depression in primary care: current and future challenges. Can J Psychiatry. 2013;58(8):442-448.

17. Britt H, Miller GC, Charles J, et al. A Decade of Australian General Practice Activity 2005-05 to 2014-15. Family Medicine Research Center. Sydney School of Public Health. Sydney, Australia: Sydney University Press; 2015. General Practice Series No. 39.

18. China Health and Family Planning Statistics Yearbook 2015. Beijing, China: Peking Union Medical College Press; 2015.

19. Liu Q, Wang B, Kong Y, Cheng KK. China's primary health-care reform. Lancet. 2011;377(9783):2064-2066.

20. Bhattacharyya O, Delu Y, Wong ST, Bowen C. Evolution of primary care in China 1997-2009. Health Policy. 2011;100(2-3):174-180.

21. Jiao $M$, Ning $N$, Li $Y$, et al. Workplace violence against nurses in Chinese hospitals: a cross-sectional survey. BMJ Open. 2015;5(3): e006719.

22. Liu R, Wong W, Lam C, Kung K, Li C, Chen Q. An assessment on the quality of general practice care in a general hospital: study of patient enablement and the factors with enablement. Chin J Gen Pract. 2017. In press.

23. Mash R, Almeida M, Wong WC, Kumar R, von Pressentin KB. The roles and training of primary care doctors: China, India, Brazil and South Africa. Hum Resour Health. 2015;13(1):93.

24. Frenk J, Chen L, Bhutta ZA, et al. Health professionals for a new century: transforming education to strengthen health systems in an interdependent world. Lancet. 2010;376(9756):1923-1958. 